\title{
Comparative Evaluation of the Two Dimensional and Three Dimensional Echocardiography in the Assessment of the Right Ventricular Functions in Nondiabetic Normotensive Hemodialysis Patients
}

\author{
AYA H. SAUDI, M.Sc.; EBTSAM I.Kh. IBRAHIM, M.D.; EHAB A. HAMDY, M.D. and \\ MAI M. SALAMA, M.D. \\ The Department of Cardiovascular Medicine, Faculty of Medicine, Tanta University, Tanta, Egypt
}

\begin{abstract}
Background: Cardiovascular diseases are one of the most important causes of death in hemodialysis patients. Few researches focused on the right ventricle functions in such patients. The rapid development of the 3D echocardiography gave a new dimension in the diagnosis and treatment plan.

Aim of Study: To compare the two dimensional (2D) and three dimensional (3D) echocardiography in the assessment of right ventricular functions in nondiabetic, normotensive, hemodialysis patients.

Patients and Methods: The study included 20 patients who were subjected to complete history tacking, full clinical examination, laboratory investigations and assessment of the right ventricular functions using 2D and 3D echocardiography.

Results: The 3D echocardiography showed statistically significant differences compared to the $2 \mathrm{D}$ echocardiography in the assessment of the right ventricular functions. Fractional area change showed a mean of $33.25 \pm 9.21$ compared to $38.05 \pm$ 7.88 of the ejection fraction gained from the $3 \mathrm{D}$ echocardiography. The sensitivity and specificity of the 3D echocardiography were $100 \%$ and $80 \%$ compared to $73.3 \%$ and $60 \%$ for the $2 \mathrm{D}$ echocardiography. Moreover the degree of accuracy of the $3 \mathrm{D}$ echocardiography was $95 \%$ compared to $70 \%$ for the $2 \mathrm{D}$ echocardiography.

Conclusion: The 3D echocardiography was more superior than the $2 \mathrm{D}$ echocardiography in the assessment of right ventricular functions in nondiabetic, normotensive, hemodialysis patients.
\end{abstract}

Key Words: Right ventricular functions $-2 D$ and $3 D$ echocardiography - Hemodialysis patients.

\section{Introduction}

RIGHT Ventricular (RV) function is a known predictor of outcome in a variety of cardiovascular

Correspondence to: Dr. Aya H. Saudi, The Department of Cardiovascular Medicine, Faculty of Medicine,

Tanta University, Tanta, Egypt diseases, including heart failure, pulmonary embolism, and myocardial infarction. Highly sensitive to alterations in pulmonary resistance, the right ventricle dilates and becomes dysfunctional in the setting of abnormally high afterload, whether acute or chronic [1]

Cardiovascular diseases are the most common cause of death in end stage renal disease patients. Several studies showed that left ventricular systolic and diastolic functions deteriorated in patients with chronic renal disease and, this was associated with worse clinical outcomes [1]. Although the relationship between Right Ventricular (RV) dysfunction and adverse outcomes has been shown in many diseases and preclinical conditions [2], little is known about RV function in nondiabetic hemodialysis (HD) patients.

Congestive heart failure is prevalent in EndStage Renal Disease (ESRD) and is a leading cause of death in such patients [3]. While most available studies focused their attention on Left Ventricular (LV) dysfunction in ESRD patients, little attention has been directed towards (RV) dysfunction. This RV dysfunction has been associated with increased morbidity and mortality in many cardiovascular diseases $[4,5]$. In a recent study, RV dysfunction was reported in two-thirds of patients on long-term dialysis; however, no data exists regarding the problem of RV dysfunction in ESRD patients before starting dialysis therapy. This may be important since detection of subclinical RV dysfunction in pre dialysis ESRD patients may help to identify patients at a higher risk of developing heart failure [6]. 
Echocardiography is the most common diagnostic tool for patients with heart disease, providing detailed information about cardiovascular morphology and hemodynamics previously available only by angiography and catheterization [7] .

There are certain limitations for accurate echocardiographic imaging of the right ventricle. Being functionally and anatomically divided into three parts [8]. So, the present study aimed to compare the $2 \mathrm{D}$ and $3 \mathrm{D}$ echocardiography in the assessment of right ventricular functions in nondiabetic normotensive hemodialysis patients.

\section{Patients and Methods}

The present study was conducted in Cardiology Department, Faculty of Medicine, Tanta University during the period from October 2016 to July 2017 on 20 patients. Patients were recruited from the Nephrology and Dialysis Unit, Tanta University hospital. All the patients gave their written informed consents to participate in this study and. The study was approved by the Faculty Ethical Committee.

\section{Inclusion and exclusion criteria:}

Patients on regular hemodialysis sessions three times per week were included while patients with evidence of ischemic heart disease, LV dysfunction, valvular diseases, previous renal transplantation, clinical conditions that might predispose to pulmonary hypertension, diabetes mellitus, patients hematological and neoplastic diseases were excluded.

\section{Methods:}

All patients were subjected to history taking including personal, present history and the past history suggesting presence of ischemia or risk factors for ischemia such as diabetes mellitus, hypertension, smoking, obesity and dyslipidemia. General and local cardiac examination for every patient was conducted. Routine 12 lead electrocardiogram (ECG) was done for the patients to detect changes suggestive of coronary artery disease. Routine laboratory investigations including kidney function test, random blood sugar and arterial blood gases were performed.

\section{Echocardiographic examination:}

All patients were subjected to 2D and 3D echocardiography for the assessment of RV functions. Echocardiographic examinations were done with Vivid 9 dimension (General Electric Medical Systems, Horten, Norway) equipped with a 2.5$\mathrm{MHz}$ variable-frequency transducer $\mathrm{S}$ probe for 2D imaging and V3 Matrix array transducer for 3D echocardiography. Standard views (parasternal long and short axis, apical four, five and two chamber, subcostal and suprasternal views) with ECG tracing were obtained in 2D modes.

\section{A- Two dimensional assessment of $R V$ function:}

\section{- $R V$ fractional area change:}

A quantitative evaluation of the RVEF by RV Fractional Area Change (FAC) was done from apical four chamber view focused on RV. Tracing of RV endocardial borders both in systole and diastole without tracing of tricuspid valve leaflets or endocardial trabeculae [13]. Right ventricular ejection fraction was calculated as follows:

$$
\text { RVEF2D }=\frac{(\text { RVEDA }- \text { RVESA })}{\text { RVEDA }}
$$

Where RVEDA is right ventricular end diastolic area. RVESA is right ventricular end systolic area. Normal values of RVEF by FAC (RVEF2D) ranged from $46 \%$ to $60 \%$ [13].

\section{- Tricuspid Annular Plane Systolic Excursion (TAPSE):}

TAPSE was calculated by placing an M-mode cursor through the tricuspid annulus and measuring the amount of longitudinal motion of the annulus at peak systole in the standard apical 4-chamber view. It is a measure of RV longitudinal function. TAPSE $<16 \mathrm{~mm}$ indicates RV systolic dysfunction. It is measured from the tricuspid lateral annulus [14].

\section{B- Three dimensional assessment of $R V$ function:}

\section{- Disc summation method:}

A quantities measurement of RV ejection fraction was calculated using 3D summation method (RVEFDS) which was used as the reference method owing to its high correlation with MRI derived ejection fraction in different studies. From the apical window, the right ventricle is divided into evenly spaced, parallel, horizontal slices. Manual tracing of RV endocardial boundaries was done at end-systolic and end- diastolic frames. Right Ventricular Ejection Fraction by DISC summation Method was calculated as follows: RVEFDS $=$ (RVEDV-RVESD)/RVEDV where as RVEDV is right ventricular end diastolic volume. RVESD is right ventricular end systolic volume. Also Normal values of RVEFDS ranges from 46\%-60\% [15].

\section{- Real time 3D echocardiography (RT3DE) method of assesment of RVEF:}

Real Time 3D Echocardiography (RT3DE) of the RV was obtained in full volume data sets in the parasternal short axis and apical four chamber windows. Respiration was suspended for 7 cycles 
and ECG leads were connected during the whole examination time [15].

RT3DE data sets were sliced from anteriorposterior (apical view) and from base to apex (short axis) to obtain six standardized plans (anterior, mid, posterior, basal, mid and apical views). RVEF was calculated in the same manner as the $2 \mathrm{D}$ views in each plane by calculation of the change in the $\mathrm{RV}$ area from diastolic to systolic and mean ejection fraction was derived from the six planes (M RVEF3D).

Each plane RVEF3D = (RVEDA-RVESA $) /$ RVEDA. The mean RVEF3D (MRVEF3D) = sum of $6 \mathrm{RVEF} 3 \mathrm{D} / 6$ where is RVEDA is right ventricular end diastolic area and. RVESA is right ventricular end systolic area.

\section{Results}

\section{The study populations:}

The study was conducted on 20 patients. The patients' ages ranged from 19-77 years with a mean of $44.9 \pm 16.2$ years including 9 male patients and 11 female patients. The study included 5 smokers and 11 dysllipidemic. The mean BMI of the 20 patients was $23.7 \pm 3.6 \mathrm{~kg} / \mathrm{m}^{2}$, one patient was underweight, 12 average patients, 6 overweight and one obese patient with a range of $18-32 \mathrm{~kg} / \mathrm{m}^{2}$.

\section{Echocardiographic data:}

The mean right ventricle ejection fraction was $38.0 \pm 7.9 \%$ using the real time $3 \mathrm{D}$ method compared to $38.05 \pm 8.8$ when measured by the $3 \mathrm{D}$ disc method without statistically significant differences, Fig. (1). Moreover the mean right ventricular ejection fraction was $33.25 \pm 9.21 \%$ by the $2 \mathrm{D}$ method compared to $38.05 \pm 7.88 \%$ with the $3 \mathrm{D}$ disc methods with a statistically significant differences $(p=0.001)$, (Table 1).

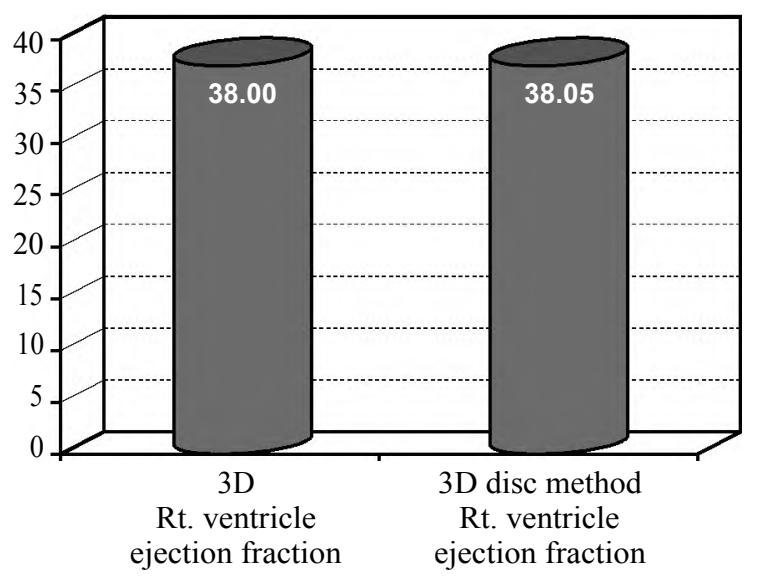

Fig. (1): The right ventricle Ejection Fraction (EF\%) measured by $3 \mathrm{D}$ using the disc.

Table (1): The right ventricular ejection fraction by $2 \mathrm{D}$ versus 3D echocardiography disc method.

\begin{tabular}{lccccc}
\hline RV & 2D & 3D disc method & & \\
$\begin{array}{l}\text { function } \\
(\mathrm{EF} \%)\end{array}$ & $\begin{array}{c}\text { Echocardiography } \\
\text { Fractional area } \\
\text { change (FAC) }\end{array}$ & $\begin{array}{c}\text { Right ventricle } \\
\text { Ejection fraction } \\
(\mathrm{EF})\end{array}$ & $t$ & $p$ \\
\hline Mean \pm S.D & $33.25 \pm 9.21$ & $38.05 \pm 7.88$ & 3.98 & 0.001 \\
\hline
\end{tabular}

Table (2): Sensitivity, specificity and diagnostic accuracy for 2D echocardiography compared with $3 \mathrm{D}$ echocardiography disc method.

\begin{tabular}{|c|c|c|c|c|c|c|}
\hline \multirow{2}{*}{$\begin{array}{l}\text { Rt. Ventricular } \\
\text { function }\end{array}$} & \multicolumn{3}{|c|}{$\begin{array}{l}\text { 3D method echo } \\
\text { echocardiography disc }\end{array}$} & \multirow{2}{*}{$\begin{array}{c}\text { Sensitivity } \\
\%\end{array}$} & \multirow{2}{*}{$\begin{array}{c}\text { Specificity } \\
\%\end{array}$} & \multirow{2}{*}{ Accuracy } \\
\hline & Impaired & Normal & Total & & & \\
\hline \multicolumn{7}{|c|}{ 2D Echocardiography: } \\
\hline Impaired & 11 & 2 & 13 & $73.3 \%$ & $60.0 \%$ & $70.0 \%$ \\
\hline Normal & 4 & 3 & 7 & & & \\
\hline Total & 15 & 5 & 20 & & & \\
\hline
\end{tabular}

Table (3): Sensitivity, specificity and accuracy for 2D echocardiography compared with 3D echocardiography disc method.

\begin{tabular}{|c|c|c|c|c|c|c|}
\hline \multirow{2}{*}{$\begin{array}{l}\text { Rt. Ventricular } \\
\text { function }\end{array}$} & \multicolumn{3}{|c|}{$\begin{array}{c}\text { 3D echo } \\
\text { echocardiography disc }\end{array}$} & \multirow{2}{*}{$\begin{array}{c}\text { Sensitivity } \\
\%\end{array}$} & \multirow{2}{*}{$\begin{array}{l}\text { Specificity } \\
\%\end{array}$} & \multirow{2}{*}{ Accuracy } \\
\hline & Impaired & Normal & Total & & & \\
\hline \multicolumn{7}{|c|}{ 3D Echocardiography: } \\
\hline Impaired & 15 & 1 & 16 & $100.0 \%$ & $80.0 \%$ & $95.0 \%$ \\
\hline Normal & 0 & 4 & 4 & & & \\
\hline Total & 15 & 5 & 20 & & & \\
\hline
\end{tabular}




\section{Agreement between the used techniques:}

The 2D echocardiography had detected 11 of 15 patients with impaired right ventricle function giving specificity of $60 \%$ and failed to detect 4 out of 15 patients giving the sensitivity of $73.3 \%$ while the diagnostic accuracy was $70 \%$ (Table 2). Also, the 3D echocardiography had detected 15 out of 15 patients with impaired RV function giving sensitivity of $100 \%$ and failed to detect one normal patient giving the specificity of $80 \%$ while the diagnostic accuracy was 95\% (Table 3).

\section{Discussion}

Cardiovascular disease is the leading cause of mortality in patient undergoing hemodialysis, accounting for $50 \%$ of death. In particular, congestive heart failure is the most common finding in these patients and is associated with poor prognosis [9] Hemodialysis which is usually carried out through a surgically created artriovenous fistula has been associated with increased risk of pulmonary hypertension and left to right shunt leading to chronic volume overload, thus worsening right ventricular function $[\mathbf{9 , 1 0 ]}$.

Most available studies focus on left ventricular function in dialysis patients, the impact of dialysis treatments on the development of right ventricular function has not been fully investigated [11] Assessment of the Right Ventricle (RV) is challenging, as the 2 dimensional (2D) approaches to the evaluation of the size and function of the RV fail to give accurate results due to the complexity of the anatomy of the RV [12]. Several 2D echocardiography measures or indices have been proposed but none of them is of great clinical impact. The current study has employed real time 3D echocardiography as a novel method to estimate the right ventricular ejection fraction and compared it with the RV FAC method of 2D echocardiography using the disc summation method as a reference method.

In the present study, RVFAC was used to assess RV function like that reported by Anavekar et al., [13] who reported that RVFAC is a $2 \mathrm{D}$ assessment that correlates well with RVEF, determined by volumetric analysis using cardiac MRI, and is superior to two other 2D methods to assess RV function. Sakuma et al., [16] studied the RVFAC predominantly reflecting transverse contractility in the horizontal long axis plane. The mean RVFAC of the present study was $37 \pm 8.5$ which agree with with the findings reported by karavelio glu et al., [17] (40.1 \pm 7.7$)$.
In the current study, TAPSE was also used to assess systolic function of the RV. Di Lullo et al., [16]. Considered that it represents the systolic descent of the tricuspid annulus and reflects the longitudinal motion of the right ventricle. In the present study the mean TAPSE value was $15 \mathrm{~mm} \pm 2$ while in Di Lullo et al., [18] it was $18 \mathrm{~mm} \pm 4$. Although it measures longitudinal function, it has shown good correlation with techniques estimating $\mathrm{RV}$ global systolic function, such as radionuclide derived RV EF, 2D RV FAC, and 2D RV EF.

The comparison between the mean RVEF derived by RT3DE and the mean RVEF derived by the disc method showed non-significant values ( $p$ value $=0.675$ ). Meanwhile the same comparison as regarding RV FAC and disc method showed significant difference $(p$-value $=0.001)$. Van der Zwaan et al., [19-21], tested the use of RT3DE to identify $\mathrm{RV}$ dysfunction in patients with congenital heart disease who required regular monitoring of RV function. Cardiac MRI was the reference method. Forty one healthy control patients and 100 patients with congenital heart disease were examined using both RT3DE and MRI for evaluation of EDV, ESV and $\mathrm{EF}$ by delination of RV endocardial border. RT3DE results were compared to MRI and they reported $95 \%$ sensitivity, $89 \%$ specificity, and negative predictive value of $99 \%$. They concluded that RT3DE was regarded as a sensitive tool for $\mathrm{RV}$ dysfunction detection.

Moreover Jenkins et al., [22] in 2007, recruited patients who had been referred to the echocardiography laboratory for the assessment of cardiac structure and function after experiencing an acute myocardial infarction, and who were scheduled to undergo 2DE, RT3DE, and MRI. In 54 patients, $\mathrm{RV}$ involvement was suspected from standard imaging, and an additional medial RV view was obtained using RT3DE. They tested the reproducibility of RT3DE and 2D echo in assessment of right ventricular dimensions and ejection fraction when compared to cardiac MRI. They studied the $\mathrm{RV}$ volumes and ejection fraction by $2 \mathrm{D}$ echocardiography including Area-length (A-L) and the Simpson method of disc. RT3DE and CMR in 50 patients with a mean age of $61 \pm 11$. The results of this study of patients with ischemic LV dysfunction and suspicion of RV involvement indicated that the RV volume measurements using RT3DE imaging were comparable with MRI. RT3DE also provided low test-retest variation and high reproducibility of RV measurements between observers.

Conclusions, the 3D echocardiography was more superior than the $2 \mathrm{D}$ echocardiography in 
the assessment of right ventricular functions in nondiabetic, normotensive, hemodialysis patients.

\section{References}

1- CHEN S.C.1, CHANG J.M., TSAI Y.C., HUANG J.C., CHEN L.I., SU H.M., HWANG S.J. and CHEN H.C.: Ratio of transmitral E-wave velocity to early diastole mitral annulus velocity with cardiovascular and renal outcomes in chronic kidney disease. Nephron. Clin. Pract., 123 (1-2): 52-60, 2013.

2- HESSELSTRAND R., SCHEJA A., WUTTGE D.M., ARHEDEN H. and UGANDER M.: Enlarged right-sided dimensions and fibrosis of the right ventricular insertion point on cardiovascular magnetic resonance imaging is seen early in patients with pulmonary arterial hypertension associated with connective tissue disease. Scand. J. Rheumatol., March, 40 (2): 133-8, 2011.

3- STACK A.G. and BLOEMBERGEN W.E.: A crosssectional study of the prevalence and clinical correlates of congestive heart failure among incident US dialysis patients. Am. J. Kidney Dis., November, 38 (5): $992-$ 1000, 2001.

4- De GROOTE P.1, MILLAIRE A., FOUCHER-HOSSEIN C., NUGUE O., MARCHANDISE X., DUCLOUX G. and LABLANCHE J.M.: Right ventricular ejection fraction is an independent predictor of survival in patients with moderate heart failure. J. Am. Coll. Cardiol., October, 32 (4): 948-54, 1998.

5- VOELKEL N.F.1, QUAIFE R.A., LEINWAND L.A., BARST R.J., McGOON M.D., MELDRUM D.R., DUPUIS J., LONG C.S., RUBIN L.J., SMART F.W., SUZUKI Y.J., GLADWIN M., DENHOLM E.M. and GAIL D.B.: Right ventricular function and failure: Report of a National Heart, Lung, and Blood Institute working group on cellular and molecular mechanisms of right heart failure. Circulation, October 24, 114 (17): 1883-91, 2006.

6- BLEEKER G.B., STEENDIJK P., HOLMAN R., YU C., BREITHARDT O.A., KAANDORP T.A.M. and BAX J.J.: Assessing right ventricular function: The role of echocardiography and complementary technologies. Heart April, 92 (Suppl 1): i19-i26, 2006.

7- LEVEY A.S., STEVENS L.A. and CORESH J.: Conceptual model of CKD: Applications and implications. Am. J. Kidney Dis., March, 53 (3 Suppl 3): S4-16, 2009.

8- GREIL G.F., BEERBAUM P., RAZAVI R. and MILLER O.: Imaging the right ventricle: Non-invasive imaging. Heart, June, 94 (6): 803-8, 2008.

9- TRESPALACIOS F.C., TAYLOR A.J., AGODOA L.Y., BAKRIS G.L. and ABBOTT K.C.: Heart failure as a cause for hospitalization in chronic dialysis patients. Am. J. Kidney Dis., June, 41 (6): 1267-77, 2003.

10- SAID K., HASSAN M., BALIGH E., ZAYED B. and SOROUR K.: Ventricular function in patients with endstage renal disease starting dialysis therapy: A tissue Doppler imaging study. Echocardiography, October, 29 (9): 1054-9, 2012.

11-HAYASHI S.Y., ROHANI M., LINDHOLM B., BRODIN L., LIND B., BARANY P., ALVESTRAND A. and SEEBERGER ASTRID: Left ventricular function in patients with chronic kidney disease evaluated by colour tissue
Doppler velocity imaging. Nephrol. Dial. Transplant., January, 21 (1): 125-32, 2006.

12- FOALE R.A., NIHOYANNOPOULOS P., RIBEIRO P., McKENNA W.J., OAKLEY C.M., KRIKLER D.M. and ROWLAND E.: Right ventricular abnormalities in ventricular tachycardia of right ventricular origin: Relation to electrophysiological abnormalities. Br. Heart J., July, 56 (1): 45-54, 1986.

13- ANAVEKAR N.S., GERSON D., SKALI H., KWONG R.Y., YUCEL E.K. and SOLOMON S.D.: Twodimensional assessment of right ventricular function: An echocardiographic-MRI correlative study. Echocardiography, May, 24 (5): 452-6, 2007.

14- LEUNG K.Y. and BOSCH J.G.: Automated border detection in three dimensional echocardiography: Principles and promises. Eur. J. Echocardiogr., March, 11 (2): $97-$ $108,2010$.

15- JURCUT R., GIUSCA S., La G.A., VASILE S., GINGHINA C. and VOIGT J.U.: The echocardiographic assessment of the right ventricle: What to do in 2010? Eur. J. Echocardiogr., March, 11 (2): 81-96, 2010.

16- SAKUMA M., ISHIGAKI H., KOMAKI K., OIKAWA Y., KATOH A., NAKAGAWA M., HOZAWA H., YAMAMOTO Y., TAKAHASHI T. and SHIRATO K. Right ventricular ejection function assessed by cineangiography--Importance of bellows action. Circ. J., June, 66 (6): 605-9, 2002.

17- KARAVELIOGLU Y., OZKURT S., KALCIK M., KARAPINAR H. and ARISOY A.: Echocardiographic assessment of right ventricular functions in nondiabetic normotensive hemodialysis patients. Interv. Med. Appl. Sci., September, 7 (3): 95-101, 2015.

18- Di L.L., FLOCCARI F. and POLITO P.: Right ventricular diastolic function in dialysis patients could be affected by vascular access. Nephron. Clin. Pract., 118 (3): c257c261, 2011.

19- VAN DER ZWAAN H.B., HELBING W.A., McGHIE J.S., GELEIJNSE M.L., LUIJNENBURG S.E., ROOSHESSELINK J.W. and MEIJBOOM F.J.: Clinical value of real-time three-dimensional echocardiography for right ventricular quantification in congenital heart disease: Validation with cardiac magnetic resonance imaging. J. Am. Soc. Echocardiogr., February, 23 (2): 134-40, 2010.

20- NIEMANN P.S., PINHO L., BALBACH T., BLONKENHAGEN M., SIBERBACH M., BROMBERG C. and SAHN D.: Anatomically oriented right ventricular volume measurements with dynamic three-dimensional echocardiography validated by 3 -Tesla magnetic resonance imaging. J. Am. Coll. Cardiol., October 23, 50 (17): 166876, 2007.

21- FUJIMOTO S., MIZUNO R., NAKAGAWA Y., DOHI $\mathrm{K}$. and NAKANO H.: Estimation of the right ventricular volume and ejection fraction by transthoracic threedimensional echocardiography. A validation study using magnetic resonance imaging. Int. J. Card. Imaging, December, 14 (6): 385-90, 1998.

22- JENKINS C., CHAN J., BRICKNELL K., STRUDWICK M. and MARWICK T.H.: Reproducibility of right ventricular volumes and ejection fraction using real-time three-dimensional echocardiography: Comparison with cardiac MRI. Chest., June, 131 (6): 1844-51, 2007. 


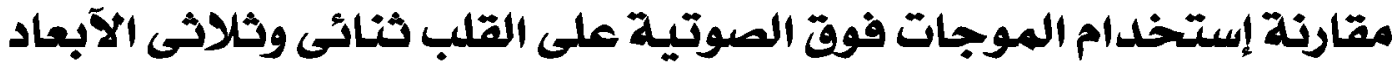

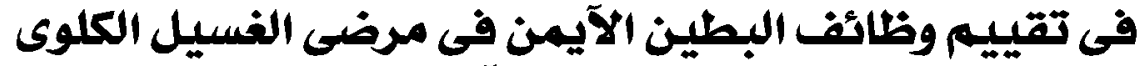

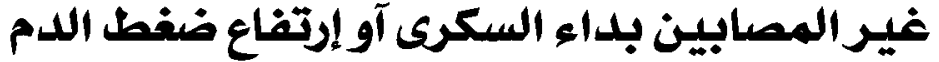

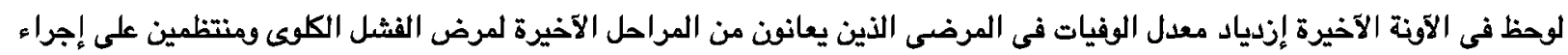

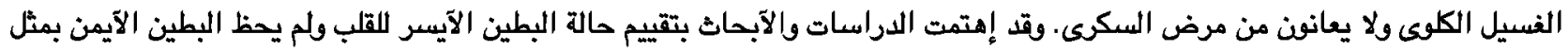

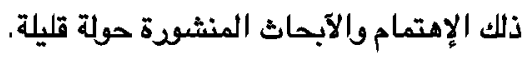

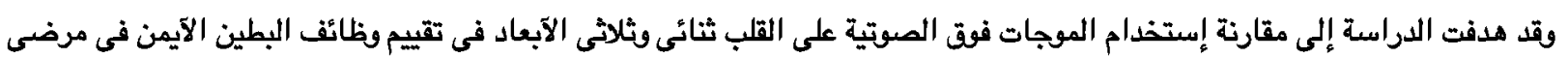

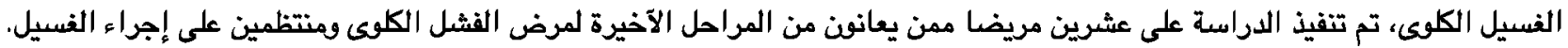

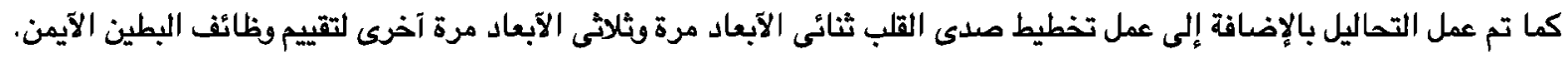
وقثد آظهرت النتائج تفوق الموجات فوق الصوتية ثلاثية الآبعاد عن الموجات فوق الصوتية ثنائية الآبعاد في تقييم وظائف البطين الآيمن

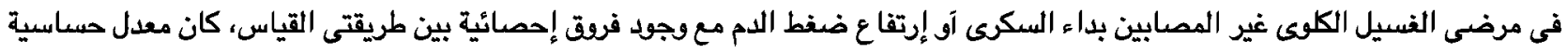

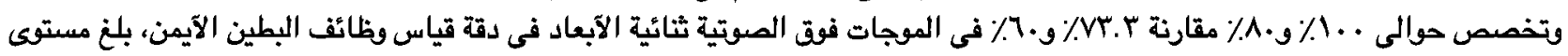

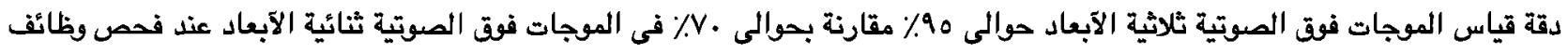

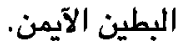

